\title{
Influence of gender and selection procedures on the academic performance of undergraduate medical students
}

\author{
Jérôme R. Lechien ${ }^{1,2,3}$, Chantal Kempenaers ${ }^{4}$, Michèle Dramaix ${ }^{5}$, Paul Linkowski ${ }^{4}$
}

${ }^{1}$ Laboratory of Phonetics, Research Institute for Language sciences and Technology, University of Mons, Mons Belgium, ${ }^{2}$ Laboratory of Anatomy and Cell Biology, Faculty of Medicine Research Institute for Health Sciences and Technology, University of Mons Mons, Belgium, ${ }^{3} \mathrm{CIUM}$ ASBL, Comite Inter Universitaire des étudiants en Médecine, Mons, Belgium, ${ }^{4}$ Psychiatry Department, Erasme Hospital, ULB Medical School, Brussels, Belgium ${ }^{5}$ Biostatistics Department, ULB Medical School, Brussels, Belgium.

Correspondence: Jerome.Lechien@umons.ac.be Tel.: + 3265373556

Fax.: + 3265373588

Received:19 June 2016

Accepted: 17 November 2016

Key words: Gender - Medical School - Selection - Undergraduate academic success.

\begin{abstract}
Objectives. To determine the impact of gender on success of students studying Medicine in Belgium from the first year (MED1) to the sixth year (MED6) of training, in the context (or not) of a selection process after three years at university. Subjects and method. Data were evaluated from two cohorts of medical students: students of the first group $(n=88)$ were not submitted to a selection process and students of the second group $(n=76)$ were submitted to a selection process after MED3. Students were enrolled in Brussels Medical School. The variables studied were the grades obtained after the first session of exams, and the student's gender. Variables were put into perspective in relation to the cohort/study year. STATA software was used for statistical analysis. Results. Linear regression showed the significant predictability of the grade obtained in MED2 for the grade obtained in MED6 for males and females only in the context of selection $(\mathrm{r}=0.51 ; \mathrm{p}<0.001)$. The impact of grades after three years on those after six years was negative in the first group of students $(\mathrm{r}=-0.17 ; \mathrm{p}=0.005)$ and positive in the second group $(\mathrm{r}=0.54 ; \mathrm{p}<0.001)$. Conclusion. These results show a moderate link between success in MED1 and success in MED6, as long as the students undergo selection. A selection system after MED1, based on medical courses, inter alia, could speed up the maturation of students. Further studies with a higher number of candidates are necessary to confirm these results.
\end{abstract}

\section{Introduction}

The likelihood of success in the first years at university is 1.6 times higher for female than for male students (1). Moreover, studies addressing the impact of gender on undergraduate medical school (MS) success in the context of early selection $(2,3)$ have reported a more stable trajectory for female than male students in the course of medical studies (4).

The aim of this research was to study: i) the trajectory of success of medical students in the French Community of Belgium (FCB) during undergraduate medical studies, and ii) the impact of gender on success in the context of a selection system conducted at the end of three years of medical studies.

\section{Subjects and methods}

\section{The medical school system in Belgium}

The MS system in the FCB has a predefined number of courses amounting to the aca- 
demic year (AY); first year = MED1, second year = MED2, etc., with a total of seven academic years (MED1-7) (Figure 1). To be able to progress to the following AY, students must pass all courses with an average of 12/20. MED1 consists of basic science courses, such as physic, chemistry and mathematics, while MED2 and MED3 consist of medical science courses including anatomy, physiology, histology, histopathology, semiology, etc. (Figure 1).

The first year (MED1) curriculum consists of basic sciences, while MED2 and MED3 include basic medical courses. From MED4 to MED7, the training program consists of medical courses and a practical program in some fields, such as surgery, pediatrics, gynecology and internal medicine. The selection process is based on the cumulated grades of the first three academic years (MED1, 2 and 3) and only a predefined number of students are able to continue the medical program. Only the students who attained their degree after 7 AY were considered. Thus, students who failed one or more AYs were excluded.

Concerning the selection system, the FCB healthcare system has been characterized by a selection system (secondary selection) for access to the various medical resident training programs (surgery, otolaryngology, general practice, etc.) after the last

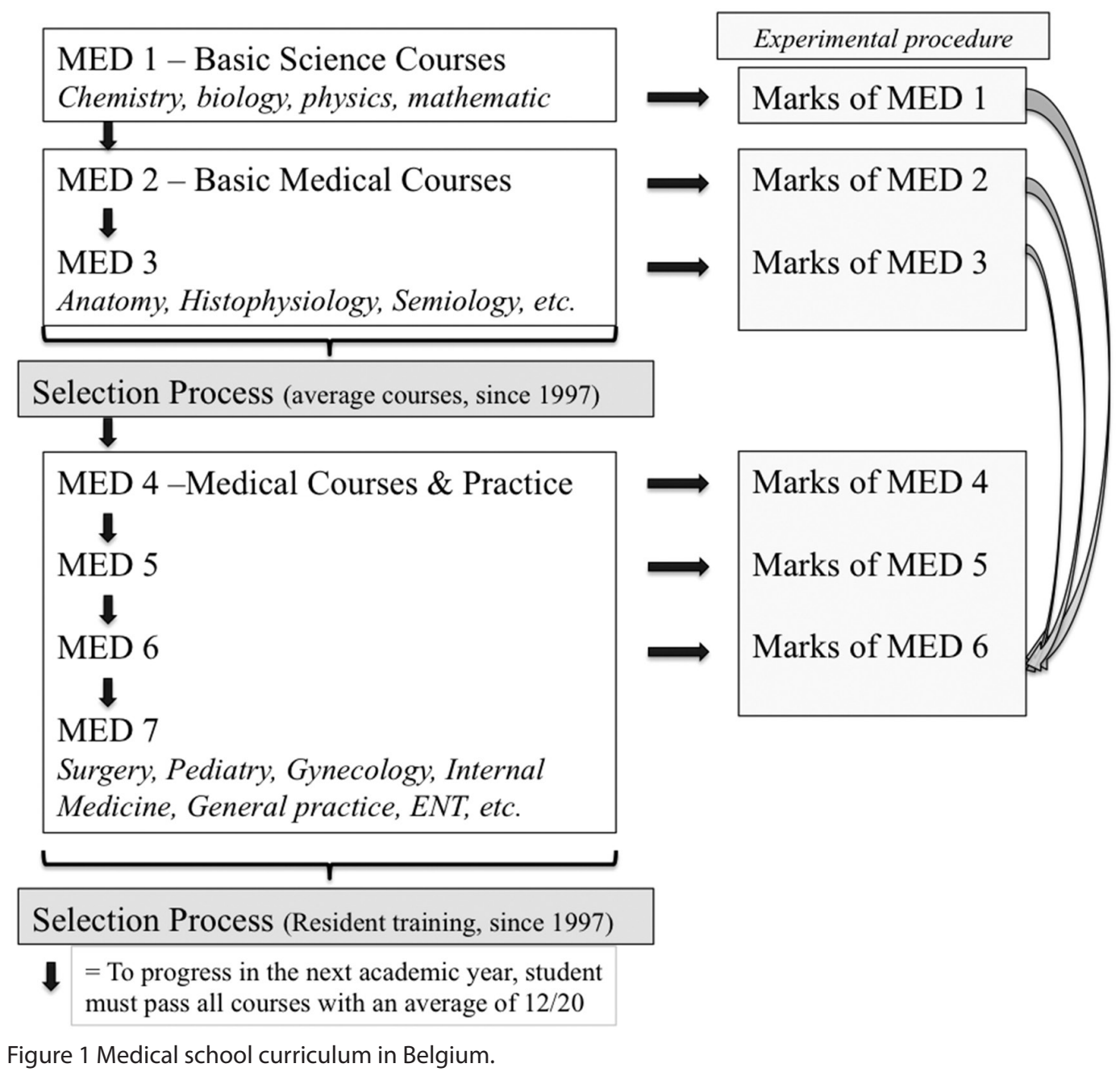


AY (MED7) since 1997. Each resident training program has a predefined number of training places. To ensure a match between the total number of residency places available and the total number of candidates at the end of MED7, FCB established a primary selection system at the end of MED3. The selection process consisted of grading the students based on the average of all courses of MED1, MED2 and MED3. All students who pass the primary selection are guaranteed access to a resident training program. Students who began their medical studies before 1997 were not subject to the selection. By contrast, students beginning since 1997 have been selected at the end of MED3, and only a predefined number are authorized to continue the medical program (Figure 1). To date, FCB is the only region in the world to use delayed selection at the end of MED3, since the classical European selection system concerns entry selection or selection after the first year of medical studies (3).

\section{Subjects and inclusion criteria}

We retrospectively studied two cohorts of students at the Medical School of the Free University of Brussels (Ethical Committee
N2012/06). The first cohort consisted of students who enrolled in MED1 in 1996-1997 $(n=88)$ who were not subject to the selection system. The second cohort was composed of students who enrolled in MED1 in 19971998 , and they were subject to the selection system after MED3 ( $n=76)$ (Figure 1 and Table 1).

\section{Variables of interest}

The following variables were analyzed: gender and grades (\%) obtained by the students at the end of each AY. These variables were studied according to the cohort and the year of medical studies (MED1, MED2, MED3, MED6).

\section{Statistical analysis}

The statistical analysis was performed using STATA v13.1 software. Comparisons of the two cohorts regarding the distribution of gender, AY success, and comparison of the grades by gender were done using the univariate Chi square test or Fisher's Student $t$ test. The contribution of each AY separately (MED1-3) to the success of MED6 (dependent variable) was assessed in a multivari-

Table 1 Cohort characteristics

\begin{tabular}{cllllll}
\hline \multirow{2}{*}{ Gender } & Cohort 1 & Grades mean & Cohort 2 & Grades mean & Total & Grades mean \\
\cline { 2 - 7 } & $\mathrm{n}$ & $\pm \mathrm{SD}$ & $\mathrm{n}$ & $\pm \mathrm{SD}$ & $\mathrm{n}$ & $\pm \mathrm{SD}$ \\
\hline Male & & & & & \\
\hline MED1 & 26 & $65.9 \pm 9.3$ & 26 & $70.2 \pm 9.0$ & 52 & $68.0 \pm 9.3$ \\
MED2 & 26 & $72.2 \pm 7.2$ & 26 & $73.4 \pm 10.0$ & 52 & $72.8 \pm 8.6$ \\
MED3 & 26 & $75.3 \pm 7.5$ & 26 & $73.7 \pm 8.5$ & 52 & $74.5 \pm 7.9$ \\
MED6 & 26 & $82.2 \pm 7.5$ & 26 & $81.7 \pm 8.7$ & 52 & $82.0 \pm 8.0$ \\
\hline Female & & & & & 106 & $68.2 \pm 9.6$ \\
\hline MED1 & 58 & $67.7 \pm 9.4$ & 48 & $68.7 \pm 9.6$ & 712 & $73.3 \pm 8.9$ \\
MED2 & 62 & $74.0 \pm 9.2$ & 50 & $72.4 \pm 8.5$ & 712 & $73.4 \pm 10.2$ \\
MED3 & 62 & $75.3 \pm 10.7$ & 50 & $71.0 \pm 8.9$ & 112 & $83.0 \pm 5.9$ \\
MED6 & 62 & $83.2 \pm 6.4$ & 50 & $82.6 \pm 5.4$ & 112 & \\
\hline
\end{tabular}

$M E D=$ Year of studying medicine. SD=Standard deviation. There were $70 \%$ female students in the first cohort versus $66 \%$ in the second cohort. 
ate way with multiple regression analysis of the gender, cohort, and their interactions with the grades obtained in MED1, MED2 or MED3. The regression coefficients of the grades obtained in MED1 to 3 are presented separately by cohort or gender. The conditions of applicability of multiple regressions were checked by residue analysis. The significance level was set at of $\alpha=0.05$.

\section{Results}

\section{Average grades according the gender and the cohort}

The average grades did not differ significantly between the cohorts, except for the average grades of MED3 since they were lower in the second cohort $(p<0.05)$. There was no difference in the average grades by gender $(\mathrm{p}=0.407)$.

\section{Success of MED6 according to successful MED1}

We did not find any significant interaction between the cohorts, the MED1 grades and those of MED6 ( $\mathrm{p}=0.130$ ). In other words, the MED1 grades predicted the MED6 grades similarly in both cohorts. The interaction between the grades in MED1 and gender was statistically significant $(\mathrm{p}=0.045)$. The effect was slightly stronger among male students (regression coefficient: female students: 0.30 ; male students: 0.51) (Table 2). The model explains the $29 \%$ variance in MED6.

\section{Success of MED6 according to successful MED2}

In the model analyzing the impact of the MED2 grades on those of MED6, no statistically significant association was observed between gender and the grades obtained in MED2, whereas the interaction between this result and the cohort was highly statistically significant $(\mathrm{p}<0.001)$. Indeed, as shown by the regression coefficients (Table 2 ), the grades in MED2 did not significantly impact the grades in MED6 in the first cohort (regression coefficient: $-0.09 ; \mathrm{p}=0.237$ ). In the second cohort, the grades in MED2 significantly impacted the grades obtained in MED6 (regression coefficient: 0.51, $\mathrm{p}<0.001)$. The model shows $23 \%$ variance for MED6.

\section{Success of MED6 according to successful MED3}

In this model, we observed a statistically significant interaction between each cohort and the impact of the grades of MED3 on those of MED6. As shown in the regression coefficient values (Table 2), the impact of the MED3 grades on the grades of MED6 was negative in the first cohort (regression coefficient: $-0.17 ; \mathrm{p}=0.005)$, and positive in the second cohort (regression coefficient: 0.54; $\mathrm{p}<0.001$ ) (Table 2).

The interaction between the grades in MED1, 2, 3, 6, and gender was presented in this Table. In a context of selection, the grades obtained in MED1, 2 and 3 significantly impacted the grades obtained in MED6 $(\mathrm{p}<0.001)$.

Table 2 Results of multiple regression models.

\begin{tabular}{lll}
\hline Variable & $\begin{array}{l}\text { B regression coefficient } \\
\text { (95\% confidence interval) }\end{array}$ & p value \\
\hline MED1 grade & & \\
\hline Female & $0.30(0.18$ to 0.42$)$ & $<0.001$ \\
Male & $0.51(0.34$ to 0.68$)$ & $<0.001$ \\
\hline MED2 grade & & \\
\hline Cohort 1 & $-0.09(-0.23$ to 0.06$)$ & 0.237 \\
Cohort 2 & $0.51(0.36$ to 0.66$)$ & $<0.001$ \\
\hline MED3 grade & & 0.005 \\
\hline Cohort 1 & $-0.17(-0.30$ to -0.05$)$ & $<0.001$ \\
\hline Cohort 2 & $0.54(0.39$ to 0.69$)$ & \\
\hline
\end{tabular}

$M E D=$ Year of studying medicine. 


\section{Discussion}

The classical factors involved in the academic success of students in MS relate to high school education, social background, intrinsic motivation, IQ, EQ, regularity of work, sense of self-efficacy and hours of study (5). Some of them may specifically characterize the behavior of males and females, leading to substantial gender differences in success at MS (2).

A few studies have shown a path, evolution, and gender sensitivity towards academic success at MS, and in selection systems (6). Most of the studies observed that females have significantly better grades than males in first AY, while still being under-represented in management functions and academic posts $(2,6)$. These authors suggested that the gender differences in academic performance may be explained by females having a more positive attitude to academic work than the males, as males are generally less engaged in their studies, and perhaps less well adapted to the university environment $(2,7)$. It is important to emphasize that some studies did not find significant gender differences in adaptation to university life, notably regarding the development of working methods (8).

Regarding success in the last AY of medical studies, some studies showed that women are more efficient in non-cognitive skills, such as empathy and communication. This point gives them an advantage, in terms of overall performance in the last years of training, since these AY are characterized by clinical training where the non-cognitive skills are well used (9).

The present report fuels the current controversy regarding the effect of gender on overall performance. The impossibility of drawing clear conclusions from related studies is probably secondary to the methodological and epistemological differences between the studies. For example, in the present study, only students who had succeeded in their studies were included in the analysis, and those who had failed one or more AY were excluded. The latter included a large number of male students in MED1. Other studies did not approach the analysis in a similar manner, which may have resulted in a comparison bias $(2,9)$.

Secondly, our results reported the existence of a moderate relationship between the grades of the first year students (MED1, 2 and 3) and the grades of MED6, especially a weak link between the grades of MED1 and MED6, which is the AY corresponding to clinical internships. These observations are consistent with the current literature, since it has been repeatedly demonstrated that the grades obtained in the basic sciences at the start of the medical program, or at the end of MED1, are not predictive of success in the final $\mathrm{AY}$ and the clinical skills of the future physician $(10,11)$.

Thirdly, our results highlight that students subjected to selection after year three adapted better to the university environment than students who did not undergo the selection process. A better prediction of final year grades was observed from the "selection group's" first year grades, especially for male students. This may be explained by suggesting that males may have reached their full potential quicker than females in the context of selection.

Recent investigations have shown that early selection could promote competition, leading to higher positive anxiety in female than in male students, and, in this context, female students are more motivated to achieve their goals. As for male students, they may perceive failure as a loss of personal worth and are more likely to avoid any risk of failure, unless they are particularly confident or intrinsically motivated (2). Psychological studies reported that the fear of failure, procrastination and self-confidence, are particular male characteristics, 
especially in less or unmotivated students, while anxiety and the value attributed to performance could be higher among female students (2). These theoretical differences could explain the results, reducing the difference between female and male students for MED2 grades predicting MED6 grades, if that filter is used. Indeed, it may be postulated that in MED2, male students have already undergone initial selection, simply related to their success in MED1, and the remaining males represent a group of motivated and relatively confident students. Our results could also suggest that the awareness of the existence of the filter after MED3 discouraged some male students to enroll in the MS program, out of fear of failure. Thus, the residual males engaged in the MS program could represent confident, mature and very motivated students. Another bias that may occur is the fact that professors could differently assess students who are subject to selection than students who are not, leading to subtle differences in their grades.

\section{Limitation of study}

The first weakness of the present study concerns the relatively low numbers of students included. The second weakness concerns the single-center aspect, which reduces its ability for generalization to other medical schools.

\section{Conclusion}

The debate about success in medical studies, and its predicting factors in the case of selection, makes sense in the world context of regulation of health care supply. The present study suggests that, in a case where a selection process is needed, an early selection system could accelerate the maturation of many candidates, including males, who adapt better to the academic environment and quickly adopt their final mode of work- ing. If selection is needed, our findings also support the importance of using it on medical courses.

\section{What is already known on this topic}

A growing number of females are enrolling in medical school programs in European countries. It seems that they are able to succeed better than male students, especially in the context of early selection systems. To date, no study has been interested in the impact of gender on medical program success, particularly in the context of selection after the third year of the undergraduate medical school program.

\section{What this study adds}

The students who were subject to a filter system after three years at medical school adapted better to the university environment when compared with the group of students that did not undergo the selection process. Better prediction of final year grades in the medical school program was observed using the first year grades, especially for male students. The awareness of the existence of a filter after three years at medical school could discourage some male candidates from enrolling in the medical school program, out of fear of failure.

Acknowledgments: Professor Janet Tuškan, native English speaker for her collaboration in proofreading of the article.

Authors' contributions: Conception and design: JRL, $\mathrm{MD}, \mathrm{CK}$, and PL; Acquisition, analysis and interpretation of data: CK, MD and JRL; Drafting the article: CK and JRL; Revising it critically for important intellectual content: PL, JRL, and MD; Approved final version of the manuscript: PL, MD, and CK.

Conflict of interest: JRL is a former student representative who has worked on the topic of selection in medical school. The authors declare that they have no conflict of interest.

\section{References}

1. Vermandele C, Dupriez V, Maroy C, Van Campenhoudt M. Success at University: the impact of the family culture [in French]. Les cahiers de recherche du Girsef. 2012;87.

2. Masson AM, Hoyois P, Cadot M, Nahama V, Petit F, Ansseau M. Girls are more successful than boys at the university. Gender group differences in models integrating motivational and aggressive components correlated with Test-Anxiety [in French]. Encephale. 2004;30(1):1-15.

3. Fayolle AV, Passirani C, Letertre E, Ramond A, Perrotin D, Saint-André JP, et al. Predictive valid- 
ity of selection process in medical school, a systematic review of the literature [in French]. Presse Med. 2016;45(5):483-94.

4. Nori Z. Gender differences creativity, academic achievement (mathematics, sciences and language of literature) among high school in city of Shiraz, Iran. Shiraz: University of Shiraz; 2002.

5. Chew BH, Zain AM, Hassan F. Emotional intelligence and academic performance in first and final year medical students: a cross-sectional study. BMC Med Educ. 2013;27;13:44.

6. Puljak L, Kojundzic SL, Sapunar D. Gender and academic medicine: a good pipeline of women graduates is not advancing. Teach Learn Med. 2008;20(3):273-8.

7. Sax LJ. The gender gap in college: maximizing the developmental potential of women and men. San Francisco: Jossey-Bass; 2008.
8. Chamorro-Premuzic T, Furnham A. Mainly Openness: The relationship between the Big Five personality traits and learning approaches. Learning and Individual Differences. 2009;19(4):524-9.

9. Lumsden MA, Bore M, Millar K, Jack R, Powis D. Assessment of personal qualities in relation to admission to medical school. Med Educ. 2005;39(3):258-65.

10. Reede JY. Predictors of success in medicine. Clin Orthop Relat Res. 1999;(362):72-7.

11. Veloski JJ, Callahan CA, Xu G, Hojat M, Nash DB. Prediction of students' performances on licensing examinations using age, race, sex, undergraduate GPAs, and MCAT scores. Acad Med. 2000;75(10 Suppl):S28-30. 